\title{
Facile Synthesis of a Tin Oxide-Carbon Composite Lithium-Ion Battery Anode with High Capacity Retention
}

Jason A. Weeks, ${ }^{\dagger}$ Ho-Hyun Sun, $\neq$ Hrishikesh Srinivasan, $\neq$ James Burrow, ${ }^{\dagger}$ Joseph V. Guerrera, ${ }^{\dagger}$ Melissa L. Meyerson, ${ }^{\dagger}$ Andrei Dolocan,$\perp$ Adam Heller,$\neq$ and C. Buddie Mullins ${ }^{*}+\neq$

${ }^{\dagger}$ Department of Chemistry, $\neq$ Department of Chemical Engineering, $\perp_{\text {Texas Materials Institute, }}$ The University of Texas at Austin, Austin, Texas 78712, United States

*Corresponding Author- Email: mullins@che.utexas.edu

\section{Supporting Information}

Synthesis and Analysis of Ditin Citrate Precursor. The precursors of the tin oxide-carbon $\left(\mathrm{SnO}_{\mathrm{x}}-\mathrm{C}\right)$ composite are sucrose and ditin citrate. Ditin citrate is not available commercially, therefore our group was required to synthesize the material in house. Synthesis of ditin citrate consists of a facile anion exchange precipitation reaction in which chloride from tin chloride is exchanged with citrate (deprotonated form of citric acid) in basic conditions (Scheme S1). ${ }^{1}$ Basic details about the reaction can be found in the experimental section of the manuscript. The purpose of the next passage is to clarify specific steps taken during the reaction and provide
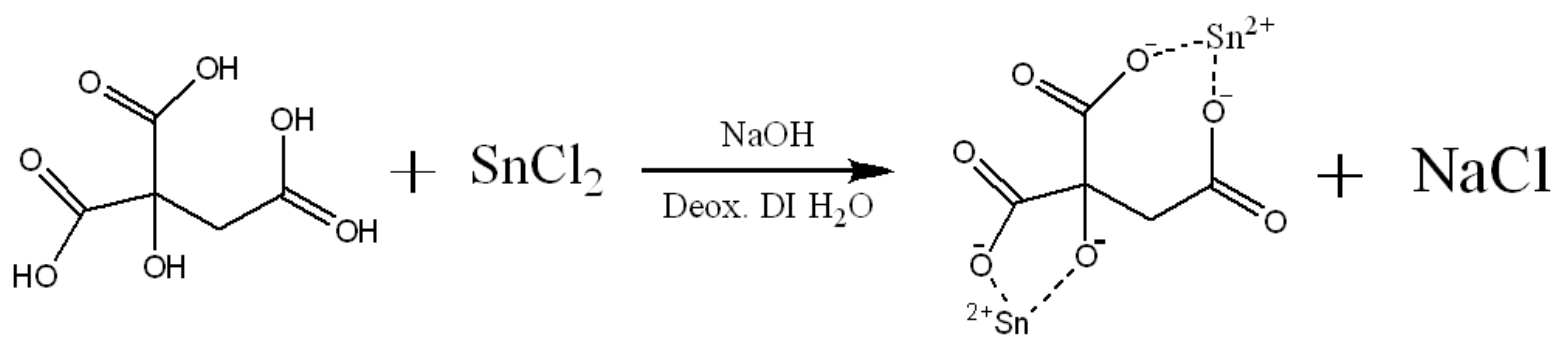

Scheme S1. Anion exchange reaction between tin chloride and citric acid.

evidence for the successful synthesis of the product. This reaction is carried out in deoxygenated water to prevent the formation of tin oxide. Furthermore, care should be taken for the introduction of $\mathrm{NaOH}$ into solution because tin hydroxide (a coarse, black by-product) can be formed if the solution rises above a $\mathrm{pH}$ of 12 . Therefore, slow addition of the $\mathrm{NaOH}$ is preferred since regions of high $\mathrm{pH}$ could generate this product and due to the insolubility of the by-product 
this formation is irreversible. With the slow addition of the $\mathrm{NaOH}$, ditin citrate can be preferentially formed. Water and ethanol were used to remove leftover salts from the final product. Ditin citrate is an incredibly insoluble product: this has been noted in previous literature and our own experience. No previous diffraction patterns have been published for this material; therefore, solid state $\mathrm{C}^{13}$-NMR, conducted with an Avance III $400 \mathrm{mHz} \mathrm{NMR}$, was used to determine the purity of the product (Figure S1). The sample spin rate was maintained at $5 \mathrm{kHz}$. Ppm shifts induced by the complexation of tin and the alteration of regions previously containing

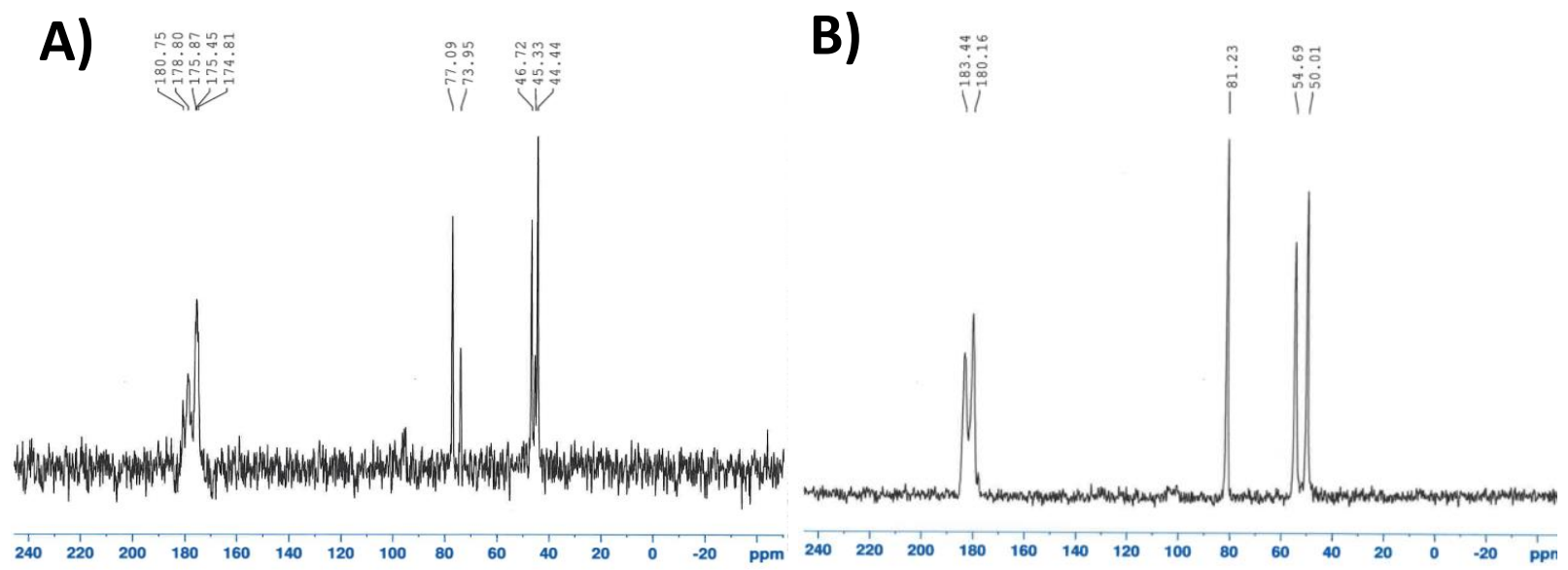

Figure S1. Resulting $\mathrm{C}^{13}$-NMR spectra for A) citric acid and B) ditin citrate.

$\mathrm{C}-\mathrm{H}$ functionalities, affirm the successful fabrication of ditin citrate. Furthermore, the peaks of these spectra match up with those found in previous literature. ${ }^{1}$

Thermal Gravimetric Analysis (TGA). To obtain a basic understanding of the thermal decomposition of the precursors, thermal gravimetric analysis was conducted on each constituent. Thermographs were retrieved using a Mettler Toledo TGA/DSC 1 STAR ${ }^{\mathrm{e}}$ system. Decomposition profiles were generated under a nitrogen atmosphere using a temperature window of $30-750{ }^{\circ} \mathrm{C}$ and a heat ramp of $10{ }^{\circ} \mathrm{C} / \mathrm{min}$. Sample weight ranged from 7-10 $\mathrm{mg}$. Resulting thermographs can be seen in Figure S2. 

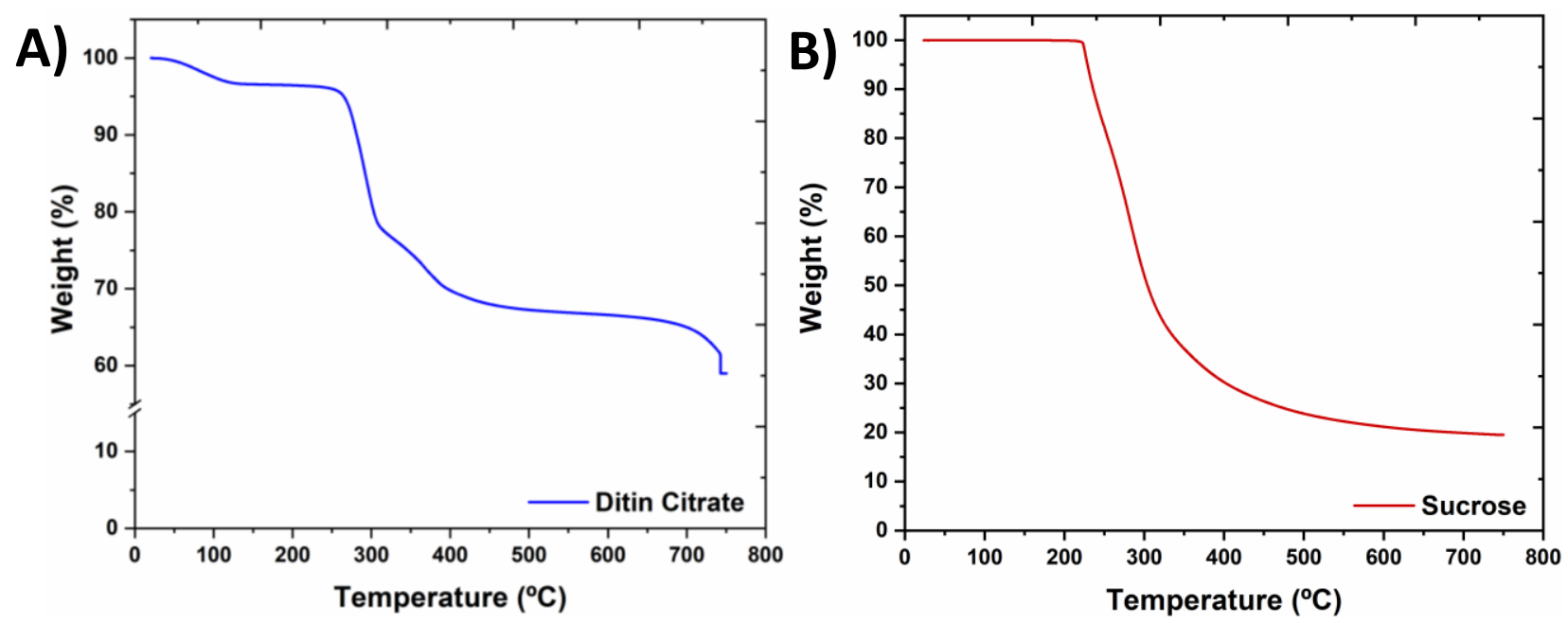

Figure S2. A-B) TGA degradation of ditin citrate and sucrose, respectively, in a nitrogen environment.

Thermal gravimetric analysis was also employed to quantify carbon content of the $\mathrm{SnO}_{\mathrm{x}}-\mathrm{C}$ composite. In ambient atmosphere, pyrolysis generated carbon can readily be burned away at temperatures exceeding $400{ }^{\circ} \mathrm{C}$. Therefore, thermographs of the $\mathrm{SnO}_{\mathrm{x}}-\mathrm{C}$ composite in air were generated to determine the wt $\%$ of carbon present in the sample. To prevent inaccuracies derived from adsorbed water, a drying period of 30 minutes at $100{ }^{\circ} \mathrm{C}$ was performed on the material before thermal decomposition was conducted. After the drying period, decomposition profiles were generated using a temperature window of $100{ }^{\circ} \mathrm{C}$ to $800{ }^{\circ} \mathrm{C}$ with a ramp rate of 10 ${ }^{\circ} \mathrm{C} / \mathrm{min}$. The resulting thermograph is shown in Figure S3. Results of this decomposition suggests that the $\mathrm{SnO}_{\mathrm{x}}-\mathrm{C}$ composite consists of approximately of 28 wt \% carbon. Since the

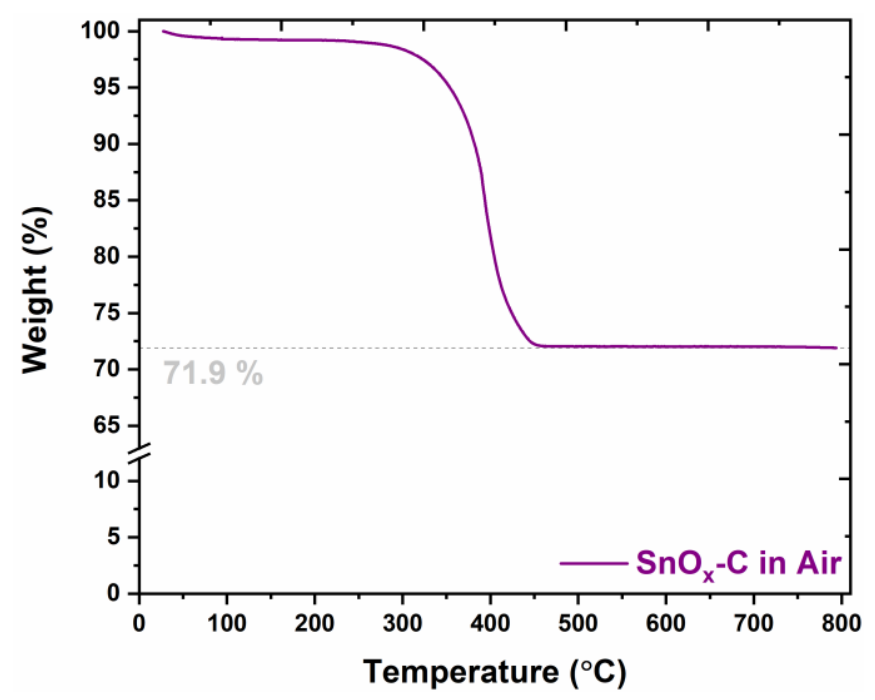

Figure S3. Thermographs for the thermal decomposition of the $\mathrm{SnO}_{\mathrm{x}}-\mathrm{C}$ composite in air. The dashed line in the figure represents the final weight of the sample post thermal degradation. 
composite consists primarily of carbon and tin oxide, an observation based on previous experiments, this insinuates that approximately $72 \mathrm{wt} \%$ of the composite consists of tin oxide.

Synthesis of the $\mathrm{SnO}_{\mathrm{x}}-\mathrm{C}$ Composite. Information retrieved from the thermal gravimetric analysis guided the temperatures used for the synthesis of the $\mathrm{SnO}_{\mathrm{x}}-\mathrm{C}$ composite. It can be noted that sucrose does not fully pyrolyze until $500{ }^{\circ} \mathrm{C}$. It is commonly known that tin oxide will thermally reduce in the presence of carbonaceous species at temperatures above $600{ }^{\circ} \mathrm{C} .{ }^{2,3}$ The aim of this study was to examine what structural motifs enhance the cycle life and reversibility of tin oxide, hence pyrolysis temperatures equal to or greater than $600{ }^{\circ} \mathrm{C}$ could not be used for electrochemical testing. To mitigate thermal reduction of tin oxide, a pyrolysis temperature of $550{ }^{\circ} \mathrm{C}$ was chosen. Pyrolysis was conducted in an argon atmosphere. Synthetic parameters for forming the composite are as follows: a Heat ramp of $10{ }^{\circ} \mathrm{C} / \mathrm{min}$ followed by a heat soak at 550 ${ }^{\circ} \mathrm{C}$ for 2 hours before the samples were slowly cooled to room temperature.

The ditin precursor contains both a carbon and tin constituent, however TGA analysis of ditin citrate reveals that slightly less than five percent of carbon is leftover after pyrolysis. This carbon content is not sufficient to combat the large volumetric expansion of tin oxide during lithiation. For this reason and due to sucrose's naturally low pyrolysis temperature, sucrose was used as a carbon containing additive for the synthesis of the $\mathrm{SnO}_{\mathrm{x}}-\mathrm{C}$. Most graphite precursors require temperatures above $700{ }^{\circ} \mathrm{C}$ in order to induce full pyrolysis. As previously stated, our composite needed to be formed below $600{ }^{\circ} \mathrm{C}$, therefore sucrose was an alluring carbon additive. To supply supplemental carbon to the composite, the final product was generated using a 1:1 ditin citrate: sucrose weight ratio. 
Four-point Probe Measurements: Electrical conductivity measurements of the pristine $\mathrm{SnO}_{\mathrm{x}}-\mathrm{C}$ material thickly coated on a glass substrate were conducted with a manual four-point resistivity probe (Lucas S302; Lucas Laboratories). Measurements were conducted by employing currents ranging from $+/-0.1 \mathrm{~mA}, 0.5 \mathrm{~mA}, 1 \mathrm{~mA}, 5 \mathrm{~mA}$, and $10 \mathrm{~mA}$; then recording the resulting potentials. The sheet resistivity was then calculated via a modified ohm's law as seen in Equation S1. This equation was derived from Smits et al. ${ }^{4}$, where $\mathrm{R}_{\mathrm{s}}$ is the sheet resistivity and

$$
R_{S}=4.53 * \mathrm{~V} / \mathrm{I}
$$

4.53 is used as a constant to represent films that are much thicker than the separation between probes. ${ }^{1}$ The resulting sheet resistivity was used to calculate the inherent resistivity and conductivity of the $\mathrm{SnO}_{\mathrm{x}}-\mathrm{C}$, which are displayed in Table S1.

Table S1: Electrical properties of the $\mathrm{SnO}_{2}-\mathrm{C}$ material determined through the use of a 4-point probe test

\begin{tabular}{c|c|c}
\hline $\mathbf{R}_{\mathbf{S}}(\boldsymbol{\Omega} / \square)$ & $\boldsymbol{\rho}(\boldsymbol{\Omega} * \mathbf{m})$ & $\boldsymbol{\sigma}(\mathbf{S} / \mathbf{m})$ \\
\hline $869 \pm 42$ & $0.0511 \pm 0.0011$ & $19.6 \pm 0.4$
\end{tabular}

X-ray photoelectron spectroscopy (XPS) Analysis. XPS spectra were recorded using a monochromated $120 \mathrm{~W}$ Al-K $\alpha 1 \mathrm{X}$-ray source $(\mathrm{h} v=1486.5 \mathrm{eV})$, hybrid optics (employing a magnetic and electrostatic lens simultaneously) and a multi-channel plate coupled to a hemispherical photoelectron kinetic analyzer. Pressure of the analysis chamber was maintained at $2 \times 10^{-9}$ Torr throughout the analysis. The spectrometer was calibrated by using $\mathrm{Ag} 3 \mathrm{~d} 5 / 2$ $(368.3 \mathrm{eV})$ peak. The photoelectron's take-off angle was normalized to the surface of the sample and $45^{\circ}$ with respect to the X-ray beam. All spectra were recorded using one sweep and an aperture slot of $300 \times 700 \mu \mathrm{m}^{2}$. Survey spectra were collected employing a pass energy of $80 \mathrm{eV}$ and $1 \mathrm{eV}$ per step. Elemental regions were collected using a pass energy of $20 \mathrm{eV}$ and $0.1 \mathrm{eV}$ per step with a total acquisition time ranging from 5 to 10 minutes. To prevent any spectral shifts caused by charging of the sample, all spectra were corrected based on the peak of typical advantageous carbon, at $284.8 \mathrm{eV} .{ }^{5,6}$ This tactic is common in most analysis of XPS spectra and prevents any inaccuracies generated from the conductivity of the sample. CasaXPS software was employed to analyze the resulting spectra. When analyzing and deconvoluting the XPS spectra of $\mathrm{SnO}_{\mathrm{x}}-\mathrm{C}$, a baseline was generated using a Shirley motif. Various literature references were used 
to determine the peak location of the functional groups and families of molecules found within the composite. ${ }^{7,8}$ The deconvoluted spectra of the composite is displayed in Figure $\mathbf{S 4}$. Quantitative analysis of the tin and carbon spectra was also done through CasaXPS, where the area of the overall peak is quantified then compared against one another and their respective expected intensities.

Examination of the $\mathrm{Sn} 3 \mathrm{~d}$ region reveals that tin remains exclusively in the tin oxide state. Furthermore, the $\mathrm{O} 1 \mathrm{~s}$ region shows that the carbon framework contains various forms of oxygen functionalities. Oxygen functionalized carbon is commonly used in Li-S batteries to induce ionic interactions which can stabilize the lithium sulfur intermediates and help prevent dissolution of these molecules in the electrolyte. We hypothesize that these oxygen functionalities are acting in 

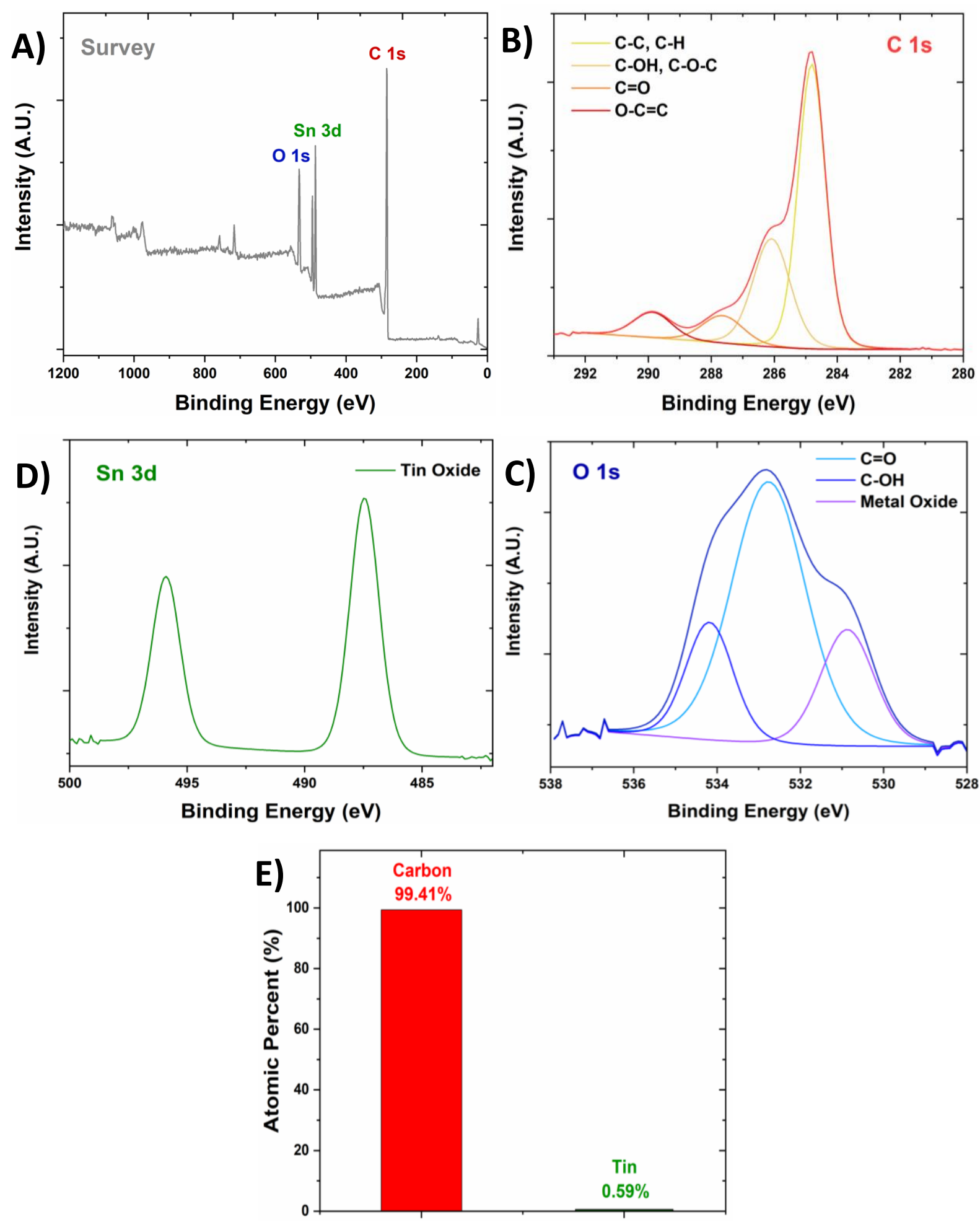

Figure S4. The resulting analysis and spectra of the XPS probe of $\mathrm{SnO}_{x}-\mathrm{C}$. A) Survey scan of $\mathrm{SnO}_{\mathrm{x}}-\mathrm{C}$ composite employing a spectral window of $0-1200 \mathrm{eV}$. Relavant peaks of the survey have been labeled in the cooresponding colors. B-D) High resolution peak scans of C 1s, Sn 3d, and O 1s; respectively. E) Comparsion of the atomic percent of carbon vs tin on the surface of $\mathrm{SnO}_{\mathrm{x}}-\mathrm{C}$, through quantitative analysis of high-resolution peak scans.

a similar manner with lithium oxide $\left(\mathrm{Li}_{2} \mathrm{O}\right)$, allowing it to be stabilized and prevent disturbances 
in the $\mathrm{Li}_{2} \mathrm{O}$ matrix during galvanostatic cycling. One of the main reasons people theorize that the formation of $\mathrm{Li}_{2} \mathrm{O}$ to be irreversible is because perturbations in the matrix will prevent successful return to the tin oxide state. Even though oxygen functionalities can reduce the electronic conductivity of carbonaceous material, we believe these functional groups are imperative for electrochemical performance since they enhance the reversibility of $\mathrm{Li}_{2} \mathrm{O}$ formation.

Previous SEM imaging suggested that the carbon support uniformly coated the tin oxide particles. Quantitative XPS analysis supports this hypothesis, showing less than 0.5 atomic \% of tin is exposed to the surface of the particle. Uniform carbon coating of the tin oxide particles is essential for high reversibility since it prevents the aggregation of tin during delithiation and provides a volumetric expansion buffer during lithiation.

Raman Spectroscopy. Raman spectroscopy is commonly used to analyze graphitic carbon and gain a better understanding of the degree of graphitization found in the carbonaceous species. The $\mathrm{D}$ and $\mathrm{G}$ bands of graphitic carbon are commonly found in the region of $1000 \mathrm{~cm}^{-1}$ $1750 \mathrm{~cm}^{-1} \cdot{ }^{9,10}$ The degree of graphitization can be determined based on the peak shape and intensity of the $\mathrm{D}$ and $\mathrm{G}$ bands, where the $\mathrm{I}_{\mathrm{D}} / \mathrm{I}_{\mathrm{G}}$ ratio permits an understanding of the degree of graphitization for a material. Since the tin oxide particles are coated using a pyrolyzed sucrosebased precursor, Raman was employed as a means of analyzing the graphitic characteristics of the framework. A Witec Micro-Raman spectrometer, equipped with a 40 watt blue laser, was used to acquire the Raman shift of the composite. The spectrometer employed a Nikon E Plan objective and camera to focus on the fine powder sample. We used an excitation wavelength of $488 \mathrm{~nm}$ and a spectral center of $2498 \mathrm{~cm}^{-1}$ to acquire the Raman shift invoked by the carbon support. The entire Raman spectrum was explored, but the only noticeable peaks derived from the D and G bands of the carbon species, as depicted in Figure S5. Spectra were acquired using a $1 \mathrm{sec}$ integration time and 20 sets of accumulations. The Witec Suite software was utilized to produce and extrapolate the spectrum. Literature values and a Voigt computation (convolution of Gaussian and Lorentzian functions) conducted through the origin software were used to deconvolute the spectra into its inherent peaks. Comparing the $\mathrm{D}$ and $\mathrm{G}$ peaks yielded an $\mathrm{I}_{\mathrm{D}} / \mathrm{I}_{\mathrm{G}}$ ratio of 0.76 , signifying that the framework consists of a relatively disordered semi-graphitized 


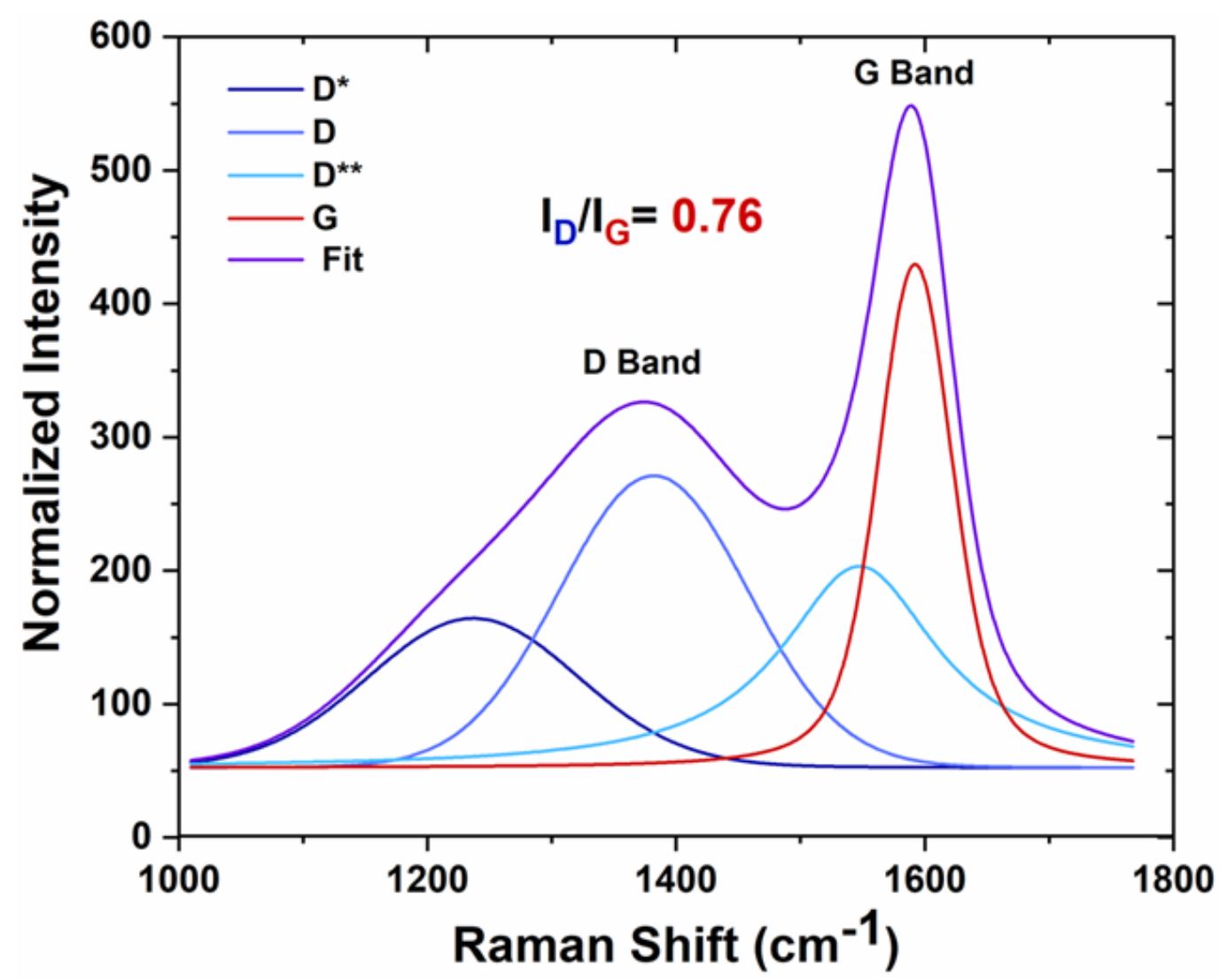

Figure S5. Raman spectrum of the $\mathrm{SnO}_{\mathrm{x}}-\mathrm{C}$ composite focused on the $\mathrm{D}$ and $\mathrm{G}$ graphitic regions. carbon. The presence of disorder and/or defects has been known to lead to increased flexibility and mechanical strength. ${ }^{11}$ We believe the defect-rich carbon present in the composite allows it to act as a buffer for the large volumetric expansion generated from lithiation of the tin oxide nanoparticles. As previously stated, large volumetric expansion can lead to fracturing of the active material, therefore leading to a physical disconnect from the current collector and the consumption of the electrolyte through the formation of new SEI.

Cross-Sectional Post-Mortem Analysis. SEM and XPS analyses have revealed that a uniform coating of carbon surrounds the tin oxide particles within the composite. To obtain an understanding of the interior architecture of the particle, cross-sectional SEM/EDX analysis was conducted. In order to obtain cross-sections of the particles, the composite material was placed inside of a silver epoxy, which aided in preventing charging during SEM analysis due to its high electrical conductivity. Embedding was conducted by mechanically mixing the material in the 
silver epoxy for ten minutes. A hardening agent was then introduced, and the mixture was allowed to cure for 12 hours under ambient conditions. An Exacto knife was then used to microtome the epoxy into small slices. The embedding of the particles in a hard epoxy allowed for the composite to remain stationary while microtoming. Clear striations generated by the blade edge can be seen on the particle surface, thereby suggesting successful cross-sectioning. Results for the SEM/EDX analysis of these cross-sections is displayed Figure 7. Cross-sections of the composite were also obtained after 400 cycles of $180 \mathrm{~mA} / \mathrm{g}$ cycling, as seen in Figure 8. Results of this imaging show that, even after long-term cycling, no visible fractures in the interior are generated and there is no change in the inner morphology.

\section{Time of Flight Simulated Imaging Mass-Spectrometry (TOF-SIMS). A TOF.SIMS 5 by}

ION-TOF GmbH (2010) instrument was employed to generate a depth profile for the reversibility of $\mathrm{Li}_{2} \mathrm{O}$ formation during galvanostatic cycling. $\mathrm{A} \mathrm{Cs}^{+}$beam $(\sim 40 \mathrm{nA}, 500 \mathrm{eV})$ was utilized to sputter a $300 \times 300 \mu \mathrm{m}$ region; Cs was chosen to decrease the work function of our material and in turn increase negative ion counts. $\mathrm{A} \mathrm{Bi}^{+}$analysis beam $(0.4 \mathrm{pA}, 30 \mathrm{keV})$ was rastered over a $100 \times 100 \mu \mathrm{m}$ area centered inside the Cs sputtered area, segmented into $256 \mathrm{x}$ 256 pixels in high current, negative analysis mode. Investigation on the reversibility of initial $\mathrm{Li}_{2} \mathrm{O}$ formation was conducted using the following samples: (1) $\mathrm{SnO}_{\mathrm{x}}-\mathrm{C}$ discharged (lithiated) through incorporation in a lithium half-cell, (2) $\mathrm{SnO}_{\mathrm{x}}-\mathrm{C}$ cycled once (lithiated then delithiated) in a lithium metal half-cell, (3) $\mathrm{SnO}_{\mathrm{x}}-\mathrm{C}$ composite soaked in the FEC: DEC electrolyte without potential applied. All samples were extracted from their respective half-cells, scraped from the current collector, washed with DEC, and dried under vacuum before TOF-SIMS analysis was conducted. Samples were kept under inert conditions utilizing a pressure-to-vacuum transfer vessel designed by the Texas Materials Institute of the University of Texas at Austin. Sample (3) was utilized as a control, generating a baseline for quantification and accounting for the formation of $\mathrm{Li}_{2} \mathrm{O}$ through SEI formation. To assure consistency throughout samples, all ion curves were normalized to their respective $\mathrm{Sn}^{-}$ion curve. This also eliminated inaccuracies that could be generated from analysis regions with variable $\mathrm{SnO}_{\mathrm{x}}-\mathrm{C}$ concentration per unit area. 
Results of the TOF-SIMs analysis are displayed in Figure S6. Quantification of the $\mathrm{Li}_{2} \mathrm{O}$
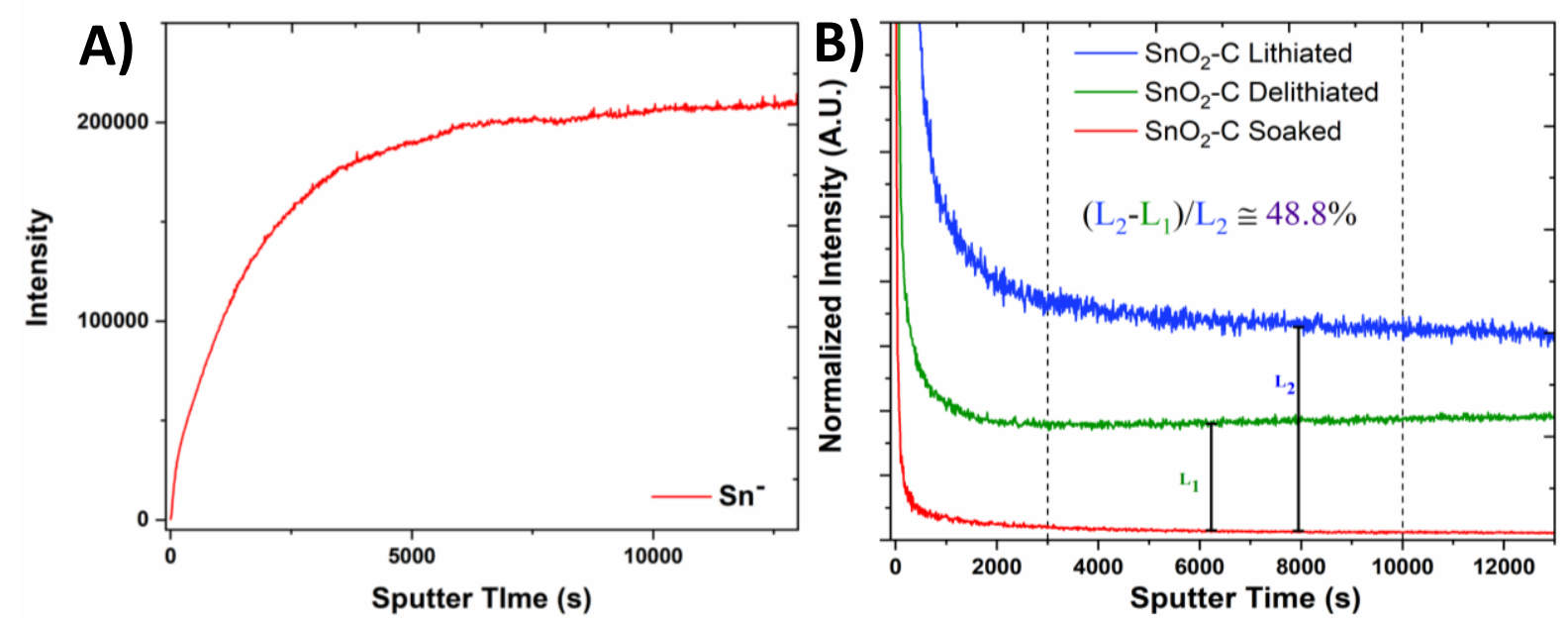

Figure S6. TOF-SIMs depth profile analysis of the $\mathrm{SnO}_{\mathrm{x}}-\mathrm{C}$ composite. A) $\mathrm{Sn}^{-}$depth profile of the composite, which was used to normalize the profile of the $\mathrm{LiO}^{-}$ions. B) Intensity of the $\mathrm{LiO}^{-}$ions throughout sputtering depth. Dashed lines represent the area (3000 s- 10000s) quantified to determine the reversibility of $\mathrm{Li}_{2} \mathrm{O}$ throughout cycling. The electrolyte-soaked sample was used as the baseline for $\mathrm{Li}_{2} \mathrm{O}$ formed through galvanostatic cycling.

reversibility was conducted using sample (3) as a baseline, then the normalized intensities of sample (1) were subtracted from the intensity of sample (2). The resulting value is representative of the amount of $\mathrm{Li}_{2} \mathrm{O}$ lost during delithiation. This value was then divided by the intensity of sample (2) to obtain the ratio of total reversible $\mathrm{Li}_{2} \mathrm{O}$. To give an accurate representative value, this process was repeated for data points at sputter times from 3,000 - 10,000s. The resulting data was averaged to determine the reversibility of the $\mathrm{Li}_{2} \mathrm{O}$ throughout the $\mathrm{SnO}_{\mathrm{x}}-\mathrm{C}$ composite. TOFSIMs analysis suggests that approximately $48.8 \%$ of the $\mathrm{Li}_{2} \mathrm{O}$ formed within the first cycle is reversible. This is a substantial improvement to other tin oxide anodes, since many materials display low reversibility of $\mathrm{Li}_{2} \mathrm{O}$ formation. ${ }^{12-14}$ The enhanced reversibility of the conversion reaction elucidates how our proposed material is able to obtain a columbic efficiency of $69.94 \%$ during the first SEI formation cycle

Electrochemical Analysis. Procedures for galvanostatic cycling were detailed fully in the experimental section of the main manuscript. Typical of many electrochemical publications, SEI formation cycles, the results of which are displayed in Figure S7, were conducted at low current 


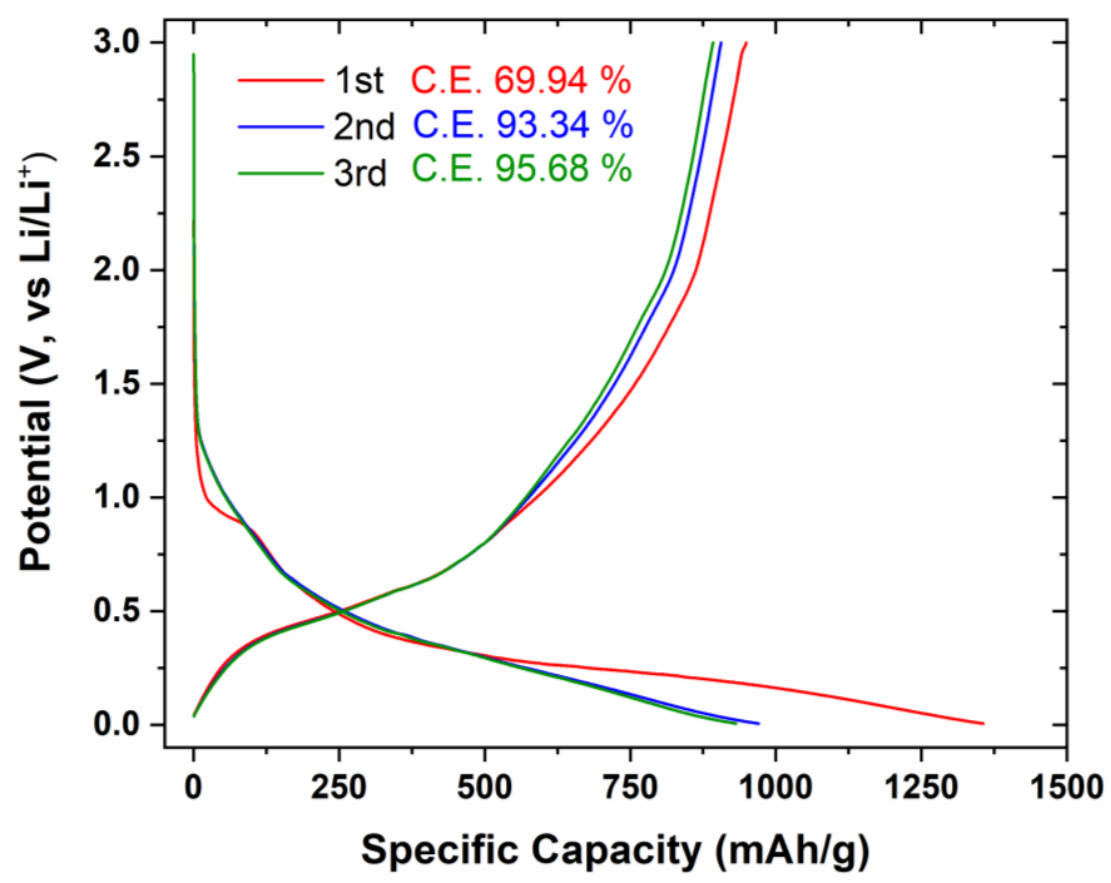

Figure S7. The charge-discharge profile of $\mathrm{SnO}_{\mathrm{x}}-\mathrm{C}$ composite at $45 \mathrm{~mA} / \mathrm{g}(\mathrm{C} / 20)$, during the SEI formation step of the electrochemical system.

densities $(\mathrm{C} / 20)$ before long-term cycling was performed. The first charge and discharge of the material results in an improved columbic efficiency (69.94\%), relative to other tin oxide electrodes. The high columbic efficiency has been attributed to the high reversibility of $\mathrm{Li}_{2} \mathrm{O}$ formation.

In the $\mathrm{SnO}_{\mathrm{x}}-\mathrm{C}$ full cell configuration, $\mathrm{NCM}$ (6-2-2) was employed as the counter-electrode. In order to have a frame of reference, half-cell electrochemical studies were conducted on the NCM material. The results of the electrochemical studies are shown in Figure S8. The results of this long-term galvanostatic cycling show the material to be a relatively reversible cathode, displaying a capacity retention of $86.5 \%$ over 50 cycles at a current density of $\mathrm{C} / 2\left(90 \mathrm{~mA} \mathrm{~g}^{-1}\right)$. 

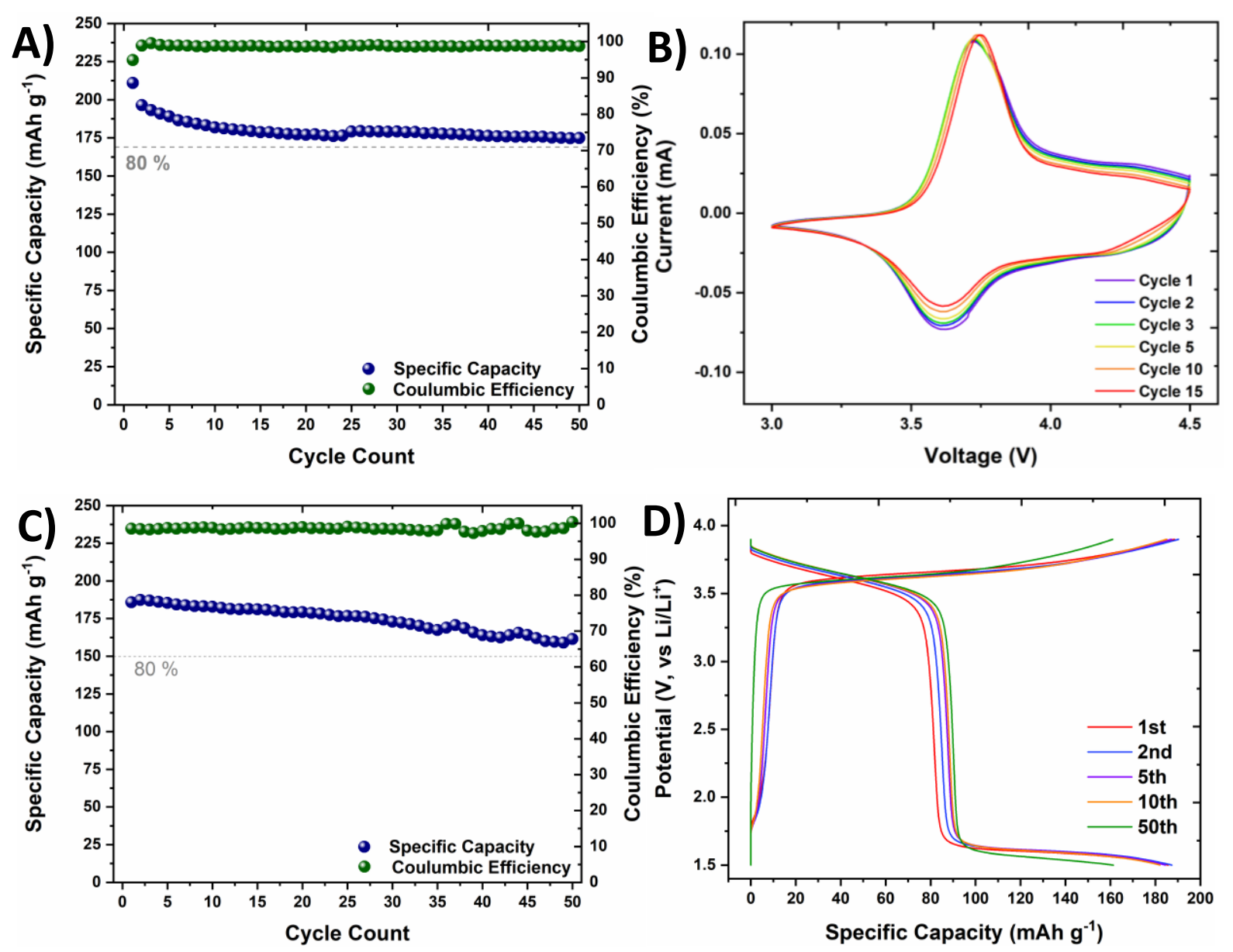

Figure S8. Electrochemical analysis of NCM (6-2-2) vs Li. A) Cycling performance at C/5 current density $\left(36 \mathrm{~mA} \mathrm{~g}^{-1}\right)$. B) Long-term cyclic voltammograms from 1 to 15 cycles generated from a 0.1 $\mathrm{mV} / \mathrm{s}$ scan rate with a potential window of $3.0 \mathrm{mV}$ to $4.5 \mathrm{~V}$. C) Cycling performance at $\mathrm{C} / 2$ current density $\left(90 \mathrm{~mA} \mathrm{~g}^{-1}\right)$. D) Charge-discharge profile at $\mathrm{C} / 2$ current density.

Comparative Samples. Systematic analysis of the lithiation mechanisms and inherent architecture of the $\mathrm{SnO}_{\mathrm{x}}-\mathrm{C}$ composite suggests that the exceptional electrochemical performance can be attributed to the employment of the unique morphology of the carbon support. To exemplify the importance of the framework, two comparative samples were generated ditin citrate $550{ }^{\circ} \mathrm{C}$ and $\mathrm{SnO}_{\mathrm{x}}$.

The ditin citrate $550{ }^{\circ} \mathrm{C}$ sample was generated by conducting a pyrolysis method identical to the formation of $\mathrm{SnO}_{\mathrm{x}}-\mathrm{C}$, however without the use of a sucrose precursor. The sucrose precursor was originally employed as a supplemental carbon additive for the formation of $\mathrm{SnO}_{\mathrm{x}}-\mathrm{C}$. Therefore, the ditin citrate $550{ }^{\circ} \mathrm{C}$ sample acts as an analogous sample used to display the need for sufficient carbon coating around the tin oxide active material. Results of the electrochemical analysis of the 
ditin citrate $550{ }^{\circ} \mathrm{C}$ sample can be found in Figure S9. Analysis of this sample showed a large
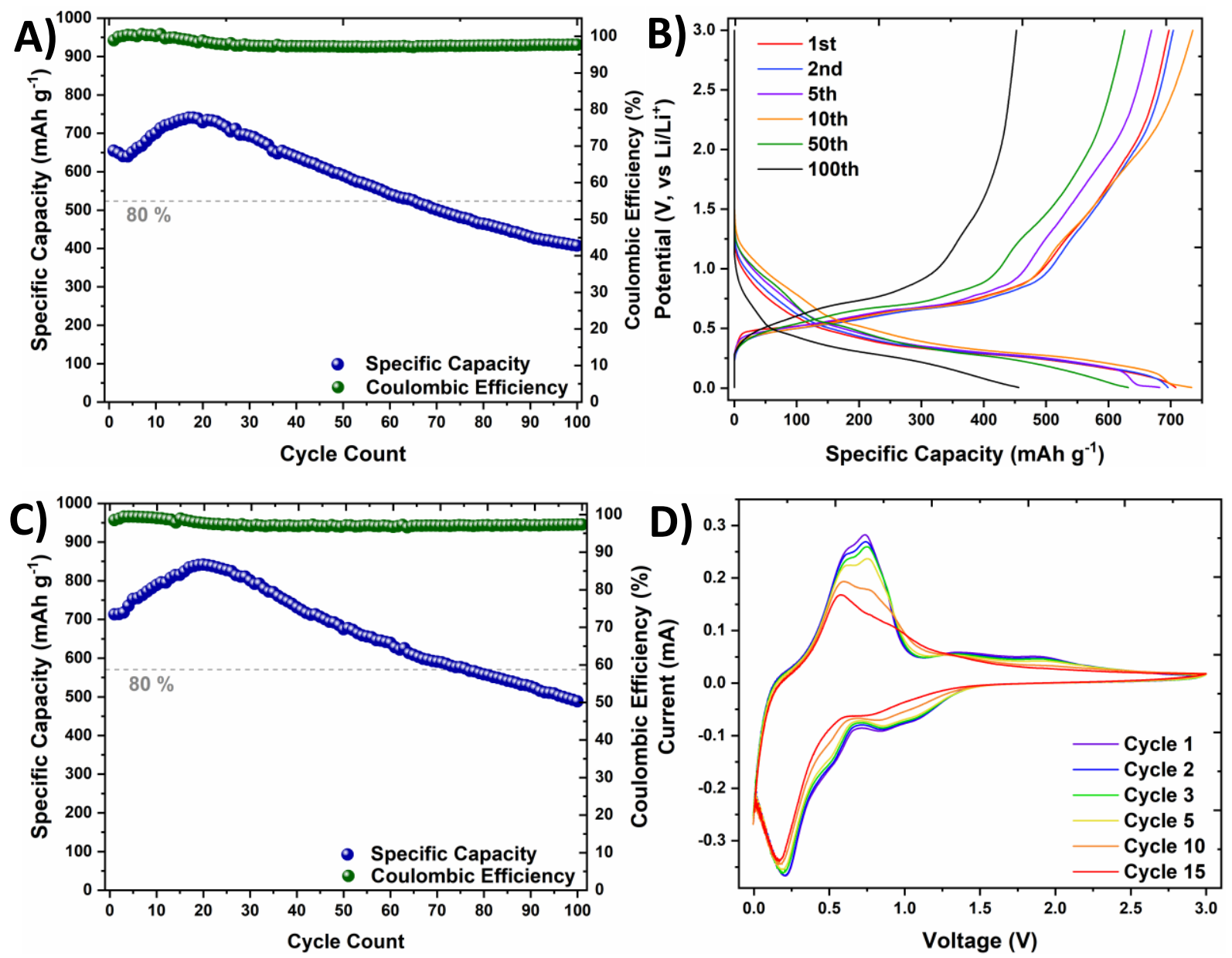

Figure S9. Electrochemical analysis of ditin citrate $550{ }^{\circ} \mathrm{C}$ vs Li. A) Cycling performance at $\mathrm{C} / 2$ current density. B) Charge-discharge profile at $\mathrm{C} / 2\left(450 \mathrm{~mA} \mathrm{~g}^{-1}\right)$ current density. C) Cycling performance at $\mathrm{C} / 5\left(180 \mathrm{~mA} \mathrm{~g}^{-1}\right)$ current density. D) Long-term cyclic voltammograms from 1 to 15 cycles generated from a $0.1 \mathrm{mV} / \mathrm{s}$ scan rate with a potential window of $5 \mathrm{mV}$ to $3.0 \mathrm{~V}$.

reduction in the electrochemical reversibility of the system. The quick degradation of the specific capacity of the material can be attributed to the insufficient carbon coating of the ditin citrate 550 ${ }^{\circ} \mathrm{C}$ sample. TGA analysis of ditin citrate (Figure S2A) suggests that approximately 5\% of carbon remains after pyrolysis. This amount of carbon is likely not sufficient to mitigate the large volumetric expansion of tin oxide during lithiation. To emphasize these results and results previously stated in the manuscript analysis of the composite without a carbon coating $\left(\mathrm{SnO}_{\mathrm{x}}\right)$ was conducted. 
Synthesis of the $\mathrm{SnO}_{\mathrm{x}}$ sample was performed by heating $2 \mathrm{~g}$ of the $\mathrm{SnO}_{\mathrm{x}}-\mathrm{C}$ composite to $550{ }^{\circ} \mathrm{C}$ in air at a heat ramp rate of $10{ }^{\circ} \mathrm{C} / \mathrm{min}$. Afterward, the temperature was held at $550{ }^{\circ} \mathrm{C}$ for 4 hours to assure the entirety of the carbon coating was removed. The result was a light beige fine powder. X-ray diffraction patterns of the material were taken to determine the composition of this product. X-ray diffraction patterns of the $\mathrm{SnO}_{\mathrm{x}}$ material are displayed in Figure S10. The

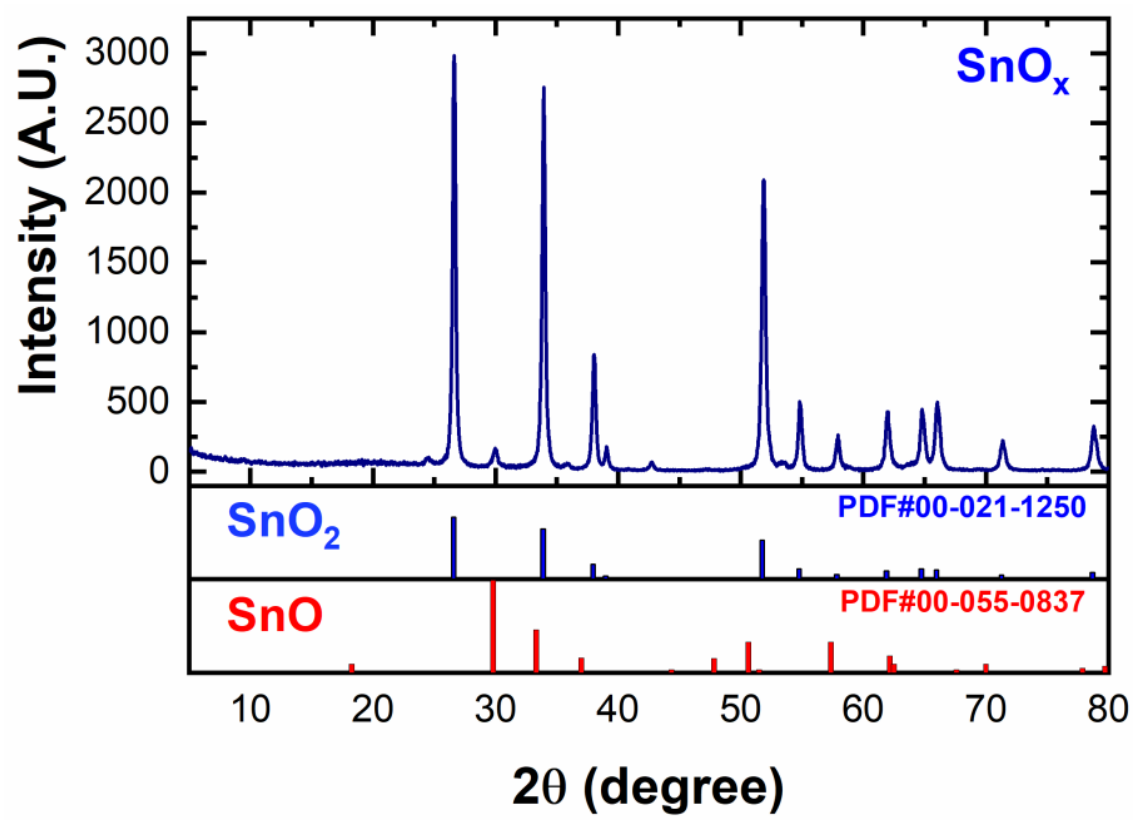

Figure S10. X-ray diffraction pattern of the $\mathrm{SnO}_{x}$ product. Literature patterns of $\mathrm{SnO}_{2}(\mathrm{PDF} \# 00-021-$ 1250) and $\mathrm{SnO}$ (PDF \#00-055-0837) have been included for reference.

resulting color of the product and the smooth baseline of the resulting X-ray diffraction pattern suggest that all of the carbon coating was successfully burned from the material. It was also noted that the diffraction pattern of $\mathrm{SnO}_{\mathrm{x}}$ suggests some of the $\mathrm{SnO}$ was oxidized to $\mathrm{SnO}_{2}$, which is typical of a metal in a thermally rich oxygen environment. SEM micrographs of the $\mathrm{SnO}_{\mathrm{x}}$ material (Figure S11) were taken to assure that the particle morphology of the tin oxide remained the same after heating. The resulting micrograph shows that the tin oxide retains the same morphology and particle size throughout the carbon burn-off procedure. Tin oxides have melting points well above $1000{ }^{\circ} \mathrm{C}$. Synthetic temperatures were therefore not high enough to induce the melting of tin oxide, thereby preventing the aggregation of the material and retaining the tin oxide morphology seen in the $\mathrm{SnO}_{\mathrm{x}}-\mathrm{C}$ composite material. 


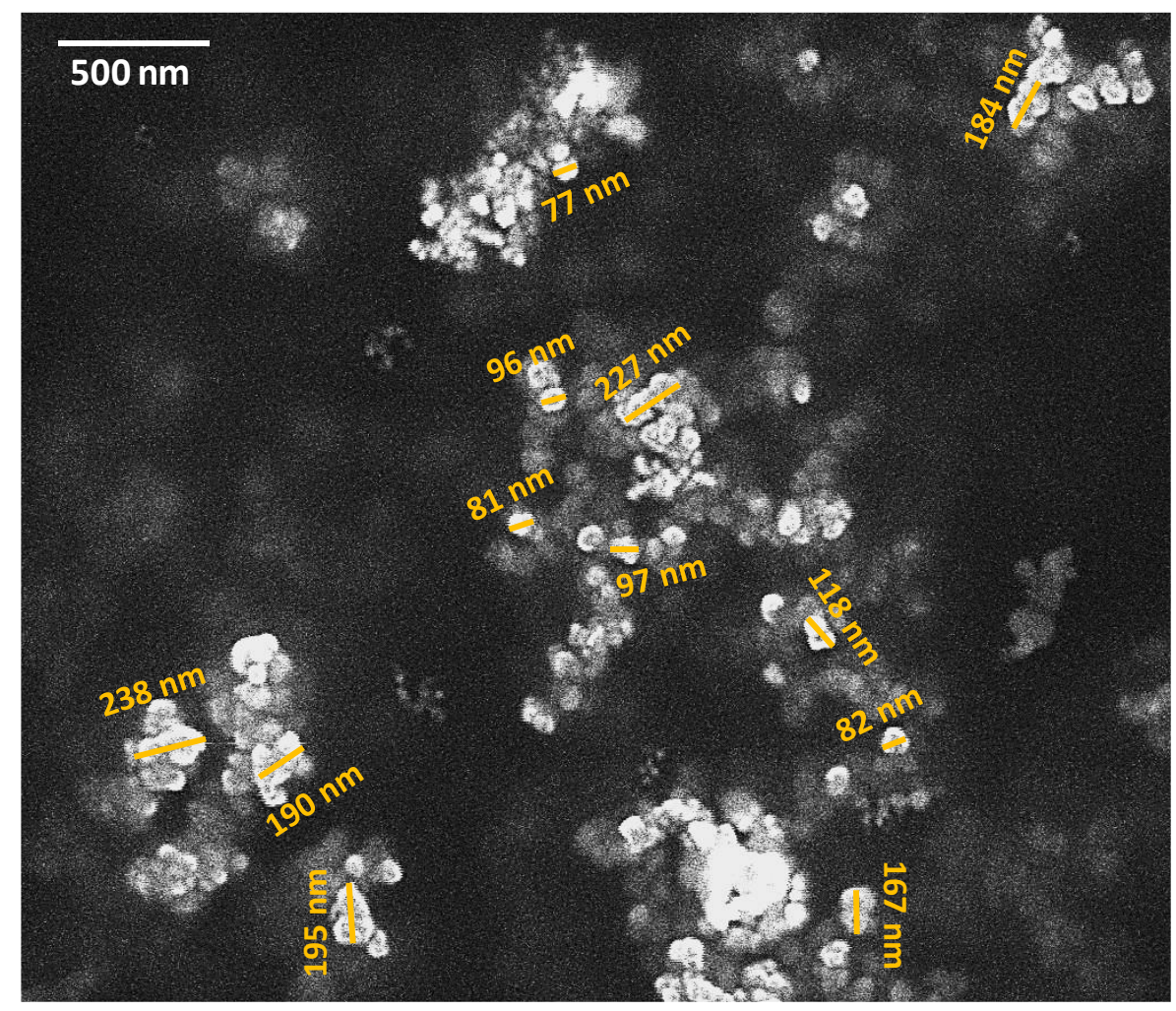

Figure S11. SEM micrograph of the $\mathrm{SnO}_{\mathrm{x}}$ product, scale bars were applied to various particles in order to permit an easy assessment of size

Electrochemical performance testing was conducted on the $\mathrm{SnO}_{\mathrm{x}}$ material to determine the effects of having no carbon coating. Results of the elecrochemical testing can be found in Figure S12. Galvanostatic performance testing of $\mathrm{SnO}_{\mathrm{x}}$ demonstrates the need for a carbon coating

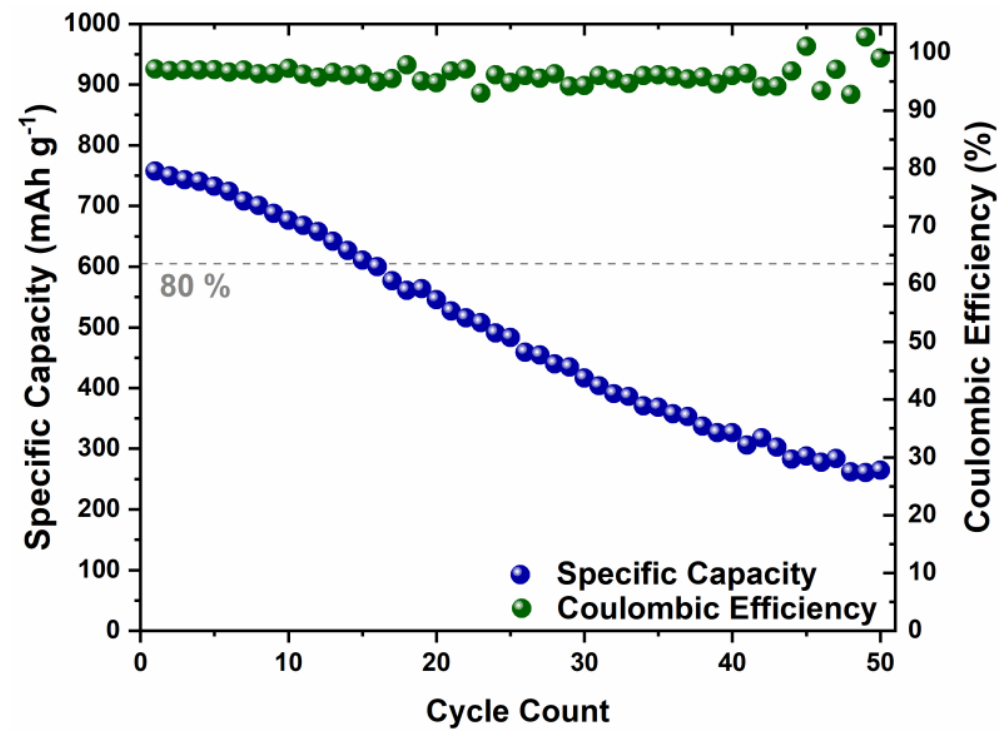

Figure S12. Long-term galvanostatic analysis of $\mathrm{SnO}_{\mathrm{x}}$ vs Li. at $\mathrm{C} / 2\left(450 \mathrm{~mA} \mathrm{~g}^{-1}\right)$ current density. 
around the tin oxide particles. The $\mathrm{SnO}_{\mathrm{x}}$ material exhibits a high initial specific capacity (757 $\mathrm{mAh} \mathrm{g}^{-1}$ ) during high current density cycling however; the $\mathrm{SnO}_{\mathrm{x}}$ material experiences dramatic capacity losses, reaching a capacity retention below $80 \%$ within 16 cycles. We hypothesize that the severe loss in effective capacity occurs in a similar manner to that shown in Scheme $\mathbf{1}$ where the material faces the agglomeration of particles, poor reversibility of $\mathrm{Li}_{2} \mathrm{O}$ formation, and particle fracture due to volumetric expansion during galvanostatic cycling. This poor electrochemical performance of $\mathrm{SnO}_{\mathrm{x}}$ exemplifies the necessity of the carbon coating, while the reduced reversibility of the ditin citrate $550{ }^{\circ} \mathrm{C}$ suggests there is an optimum amount of carbon that should be employed to maintain the high cycle life of the material.

Brunauer-Emmett-Teller (BET) Analysis. The textural properties of the $\mathrm{SnO}_{\mathrm{x}}-\mathrm{C}$ sample were characterized by nitrogen sorption isotherms at $77 \mathrm{~K}$ using a Quantachrome NOVA 2200e surface area analyzer. Ultra-high purity nitrogen and helium were obtained from Airgas, Inc. An empty $9 \mathrm{~mm}$ bulb sample cell was weighed and filled with approximately $250 \mathrm{mg}$ of $\mathrm{SnO}_{\mathrm{x}}-\mathrm{C}$. The sample cell was then heated to $200{ }^{\circ} \mathrm{C}$ under vacuum for 12 hours to degas any previously adsorbed species. After vacuum degassing, the powder-filled sample cell was backfilled with nitrogen and weighed again to calculate the degassed mass of $\mathrm{SnO}_{\mathrm{x}}-\mathrm{C}$ inside the cell. A filler rod was inserted into the sample cells, and the void volume of the sample cells were measured with helium. A bath of liquid nitrogen was employed to maintain a temperature of $77 \mathrm{~K}$ during the adsorption analysis. A nitrogen sorption isotherm was obtained by a volumetric dosing method in the relative pressure range of 0.005 to 0.99 (absolute pressure range of $3.8 \mathrm{mmHg}$ to 752.5 $\mathrm{mmHg}$ ). The resulting isotherm was analyzed quantitatively with both (1) Brunauer-EmmettTeller (BET) theory ${ }^{15}$ and (2) quenched-solid density functional theory (QSDFT). ${ }^{16}$ The BET surface area was calculated by fitting the linear segment of the initial portion of the adsorption branch of the nitrogen isotherm. NOVAwin ${ }^{\mathrm{TM}}$ software was applied to fit kernels derived from QSDFT, representing slit-shaped pore geometry, to the resulting equilibrium isotherm to quantify the pore size distribution of the $\mathrm{SnO}_{\mathrm{x}}-\mathrm{C}$ product. The total pore volume was quantified 
with the uptake at a relative pressure of 0.99 (absolute pressure of $752 \mathrm{mmHg}$ ). These quantities are summarized in Table $\mathbf{S 2}$.

Table S2. Summary of textural properties of the tin oxide-carbon composite material.

\begin{tabular}{c|c|c|c}
\hline $\begin{array}{c}\text { Average Pore Width } \\
(\mathbf{n m})\end{array}$ & $\begin{array}{c}\text { BET Surface } \\
\text { Area }\left(\mathbf{m}^{2} / \mathbf{g}\right)\end{array}$ & $\begin{array}{c}\text { Volume @ P/Po } \\
=\mathbf{0 . 9 9}(\mathbf{c c} / \mathbf{g})\end{array}$ & $\begin{array}{c}\text { Total Pore Volume } \\
(\mathbf{c c} / \mathbf{g})\end{array}$ \\
\hline $1.03 \pm 0.04$ & $210.2 \pm 8.9$ & $68.2 \pm 3.3$ & $0.1025 \pm 0.004$
\end{tabular}

The $\mathrm{SnO}_{\mathrm{x}}-\mathrm{C}$ nitrogen isotherm, Figure S13, displays a type I/IV isotherm with $\mathrm{H} 4$

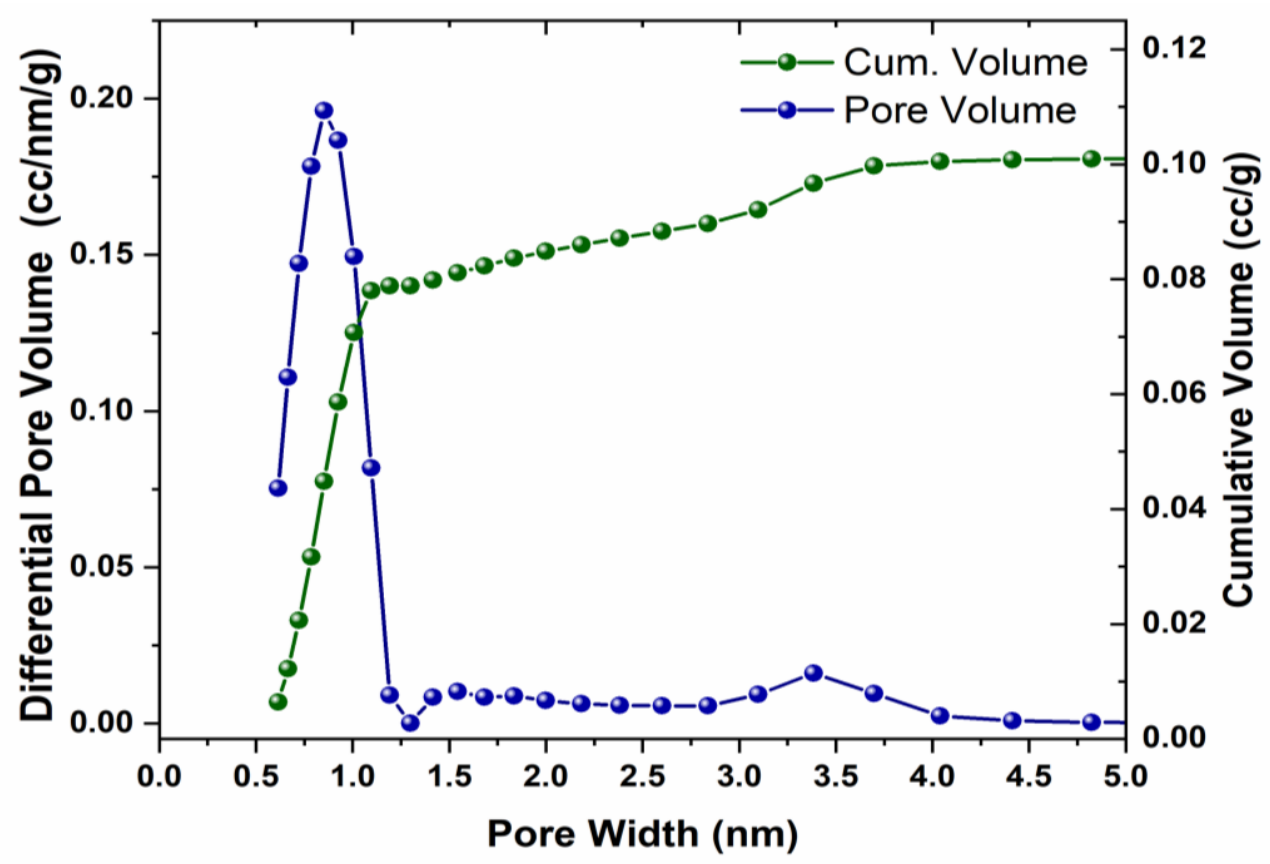

Figure S13. Pore size distribution and cumulative pore volume derived by fitting kernels derived from QSDFT to the equilibrium branch of the nitrogen isotherm surfaces assuming slit-shaped pores. Most of the porosity in this range comes from narrow micropores $<1 \mathrm{~nm}$.

hysteresis, which is characteristic of hierarchical micro/mesoporous materials. ${ }^{17}$ BET analysis suggests a surface area around $210 \mathrm{~m}^{2} / \mathrm{g}$, and QSDFT analysis elucidates this hierarchical pore size distribution with a cumulative pore volume of around $0.1 \mathrm{cc} / \mathrm{g}$ as displayed in Figure S14. Based on these analyses, we conclude that the tin oxide-carbon composite has a moderate surface area derived primarily by microporosity.

While only one isotherm and its corresponding pore size distribution are presented here, these analyses were repeated with 5 different portions of $\mathrm{SnO}_{\mathrm{x}}-\mathrm{C}$ material to probe statistical 


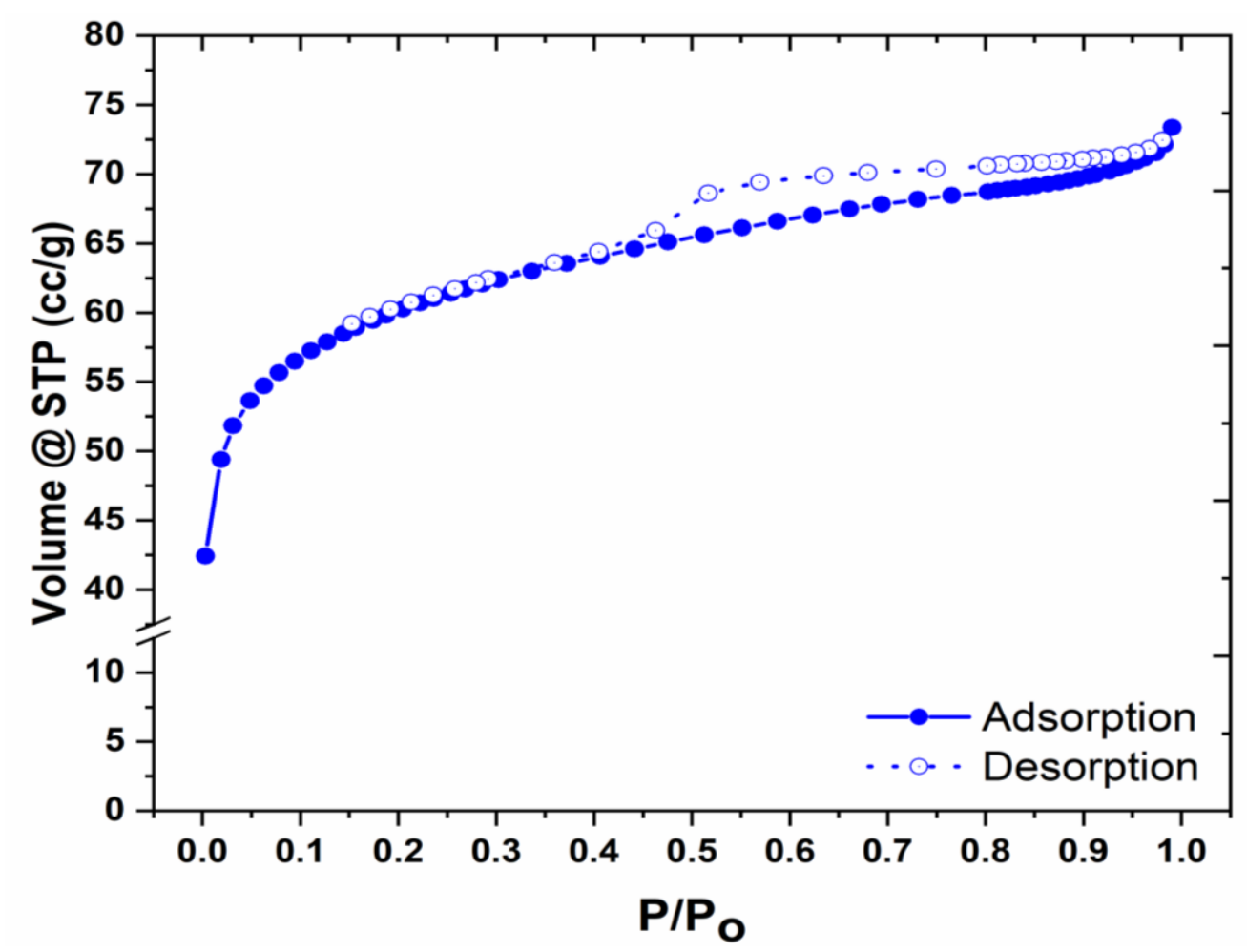

Figure S14. Complete nitrogen isotherms at $77 \mathrm{~K}$ of the tin oxide-carbon composite.

significance. Overall, all analyses show the same isotherm shape and display a coefficient of variation of approximately $4 \%$ between all the analyses done on the two batches of the $\mathrm{SnO}_{\mathrm{x}}-\mathrm{C}$ composite material.

\section{Quantification of $\mathrm{SnO}$ and $\mathrm{SnO}_{2}$}

Previous XRD analysis of the $\mathrm{SnO}_{\mathrm{x}}-\mathrm{C}$ composite (Figure 1) elucidates that the composite consists of two species of tin oxide, SnO (PDF \# 00-055-0837) and $\mathrm{SnO}_{2}$ (PDF \# 00-021-1250). In order to obtain a better understanding of the composition and inherent properties of the material, our group wanted to obtain a quantification for the concentration of each species of tin oxide. However, due to the intrinsic properties of our material and similarities in chemical environment between $\mathrm{SnO}$ and $\mathrm{SnO}_{2}$ many typical quantification methods could not be employed. For example, due to the insolubility of the $\mathrm{SnO}_{\mathrm{x}}-\mathrm{C}$ composite most methods of mass spectrometry were not possible. XPS analysis was investigated as potential route for quantification, unfortunately there is only a $0.2 \mathrm{eV}$ difference between $\mathrm{SnO}(486.5 \mathrm{eV})$ and $\mathrm{SnO}_{2}(486.7 \mathrm{eV})$. 
Previous work has shown that quantification of certain species is possible through XRD, granted that the species in question have distinct XRD spectra with very little overlap. As seen in Figure 1, $\mathrm{SnO}$ and $\mathrm{SnO}_{2}$ have very different X-ray diffraction patterns, making it possible to quantify concentration of each species through deconvolution of the X-ray diffraction pattern using the literature diffraction patterns of $\mathrm{SnO}$ and $\mathrm{SnO}_{2}$. Deconvolution of the X-ray diffraction patterns was conducted through a whole pattern fitting technique and the aid of the PDXL 2 (Version 2.6.1.2) integrated X-ray powder diffraction software. Backgrounds for the spectra were generated using a basis spline function and peak fits were conducted using a split pseudo-Voigt function.

A calibration curve generated from reagent grade standards was first used to test the accuracy of the quantification. Seven samples were used to generate the calibration curve, the actual composition and fit determined concentrations of these samples are listed below in Table S3.

Table S3. Experimental values for the known composition and fit determined composition of the standards used in the generation of the calibration curve.

\begin{tabular}{|c|c|c|c|c|c|}
\hline Sample & $\begin{array}{c}\text { Desired } \\
\text { Composition }\end{array}$ & Experimental & Composition & Deconvoluted & Composition \\
\hline (\#) & $\left(\mathrm{SnO}: \mathrm{SnO}_{2}\right)$ & SnO (wt \%) & $\mathrm{SnO}_{2}(\mathrm{wt} \%)$ & SnO (wt \%) & $\mathrm{SnO}_{2}(\mathrm{wt} \%)$ \\
\hline 1 & 100:0 & 100 & 0 & 100 & 0 \\
\hline 2 & 90:10 & 90.0 & 10.0 & 91.1 & 8.9 \\
\hline 3 & $70: 30$ & 69.9 & 30.1 & 68.8 & 31.2 \\
\hline 4 & $50: 50$ & 49.8 & 50.2 & 52.6 & 47.4 \\
\hline 5 & $30: 70$ & 30.2 & 69.8 & 32.2 & 67.8 \\
\hline 6 & 10:90 & 10.0 & 90.0 & 12.4 & 87.6 \\
\hline 7 & 0:100 & 0 & 100 & 0 & 100 \\
\hline
\end{tabular}

Samples for this curve were created by mechanically mixing reagent grade tin (II) oxide (Alfa Aesar, 99.9\%) and tin (IV) oxide (Alfa Aesar, 99.9\%), in the appropriate proportions, for 15 minutes using a mortar and pestle. The resulting mixture was then collected and its X-ray diffraction pattern was taken using a Rigaku Miniflex 600 diffractometer. A comparison of the actual sample composition versus the determined fit calculated composition is shown in Figure S15. The standard sample compositions closely match that of the composition determined through spectral deconvolution, and the linear fit of this trend displays a $\mathrm{R}^{2}=0.998$. This calibration curve 


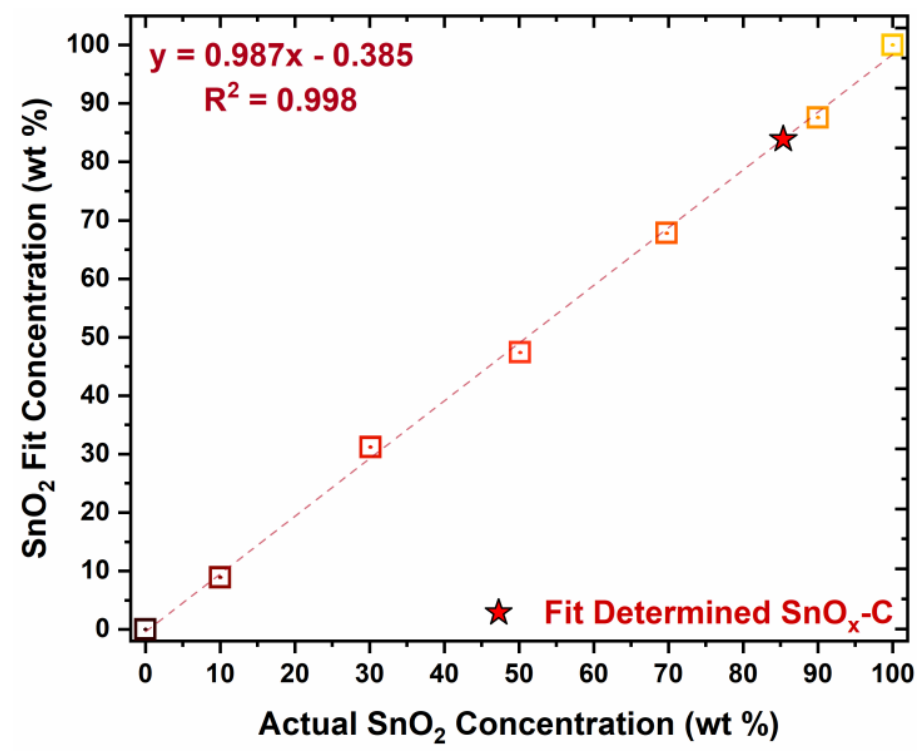

Figure S15. A calibration curve based on the experimental $\mathrm{SnO}_{2}$ concentration versus the $\mathrm{SnO}_{2}$ concentration determined through whole pattern fitting deconvolution of the X-ray diffraction pattern. suggest this technique can be used to accurately determine the concentration of $\mathrm{SnO}_{2}$ compared to $\mathrm{SnO}$.

A fit of the deconvoluted X-ray diffraction pattern for $\mathrm{SnOx}-\mathrm{C}$ is displayed in Figure S16. A residual plot for the experimental versus the deconvoluted X-ray diffraction pattern has been included in grey to demonstrate the close fitting of the spectra. Results of this deconvolution suggest that the composition of the composite consists of 85.4 wt $\% \mathrm{SnO}_{2}$ and $14.6 \mathrm{wt} \% \mathrm{SnO}$.

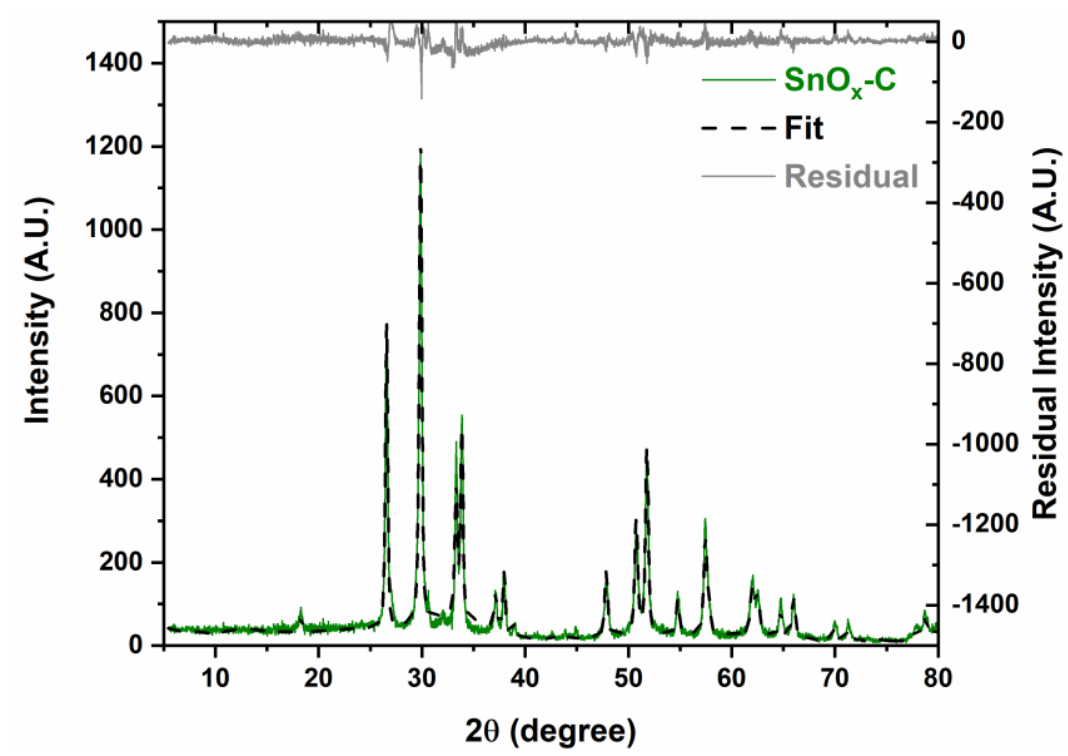

Figure S16. Whole pattern fit for the deconvolution of the $\mathrm{SnO}_{\mathrm{x}}-\mathrm{C} \mathrm{X}$-ray diffraction pattern compared to the experimental $\mathrm{X}$-ray diffraction pattern of $\mathrm{SnO}_{\mathrm{x}}-\mathrm{C}$. 


\section{References}

(1) Deacon, P. R.; Mahon, M. F.; Molloy, K. C.; Waterfield, P. C. Synthesis and Characterisation of Tin(II) and Tin(IV) Citrates. J. Chem. Soc., Dalton Trans. 1997, 0 (20), 3705-3712. https://doi.org/10.1039/A704511E.

(2) Mitchell, A. R.; Parker, R. H. The Reduction of $\mathrm{SnO} 2$ and Fe2O3 by Solid Carbon. Minerals Engineering 1988, 1 (1), 53-66. https://doi.org/10.1016/0892-6875(88)90066-0.

(3) Padilla, R.; Sohn, H. Y. The Reduction of Stannic Oxide with Carbon. MTB 1979, 10 (1), 109-115. https://doi.org/10.1007/BF02653980.

(4) Smits, F. M. Measurement of Sheet Resistivities with the Four-Point Probe. Bell System Technical Journal 1958, 37 (3), 711-718. https://doi.org/10.1002/j.15387305.1958.tb03883.x.

(5) Swift, P. Adventitious Carbon-the Panacea for Energy Referencing? Surface and Interface Analysis 1982, 4 (2), 47-51. https://doi.org/10.1002/sia.740040204.

(6) Barr, T. L.; Seal, S. Nature of the Use of Adventitious Carbon as a Binding Energy Standard. Journal of Vacuum Science \& Technology A 1995, 13 (3), 1239-1246. https://doi.org/10.1116/1.579868.

(7) Hantsche, H. High Resolution XPS of Organic Polymers, the Scienta ESCA300 Database. By G. Beamson and D. Briggs, Wiley, Chichester 1992, 295 Pp., Hardcover, $£$ 65.00, ISBN 0-471-93592-1. Advanced Materials 1993, 5 (10), 778-778.

https://doi.org/10.1002/adma.19930051035.

(8) Kövér, L.; Kovacs, Z.; Sanjines, R.; Moretti, G.; Cserny, I.; Margaritondo, G.; Pálinkás, J.; Adachi, H. Electronic Structure of Tin Oxides: High-Resolution Study of XPS and Auger Spectra. SURF INTERFACE ANAL 1995, 23 (7-8), 461-466.

(9) Ferrari, A. C. Raman Spectroscopy of Graphene and Graphite: Disorder, Electron-Phonon Coupling, Doping and Nonadiabatic Effects. Solid State Communications 2007, 143 (1), 47-57. https://doi.org/10.1016/j.ssc.2007.03.052.

(10) Ferrari, A. C.; Robertson, J. Interpretation of Raman Spectra of Disordered and Amorphous Carbon. Phys. Rev. B 2000, 61 (20), 14095-14107. https://doi.org/10.1103/PhysRevB.61.14095.

(11) Stein, I. Y.; Constable, A. J.; Morales-Medina, N.; Sackier, C. V.; Devoe, M. E.; Vincent, H. M.; Wardle, B. L. Structure-Mechanical Property Relations of Non-Graphitizing Pyrolytic Carbon Synthesized at Low Temperatures. Carbon 2017, 117, 411-420. https://doi.org/10.1016/j.carbon.2017.03.001.

(12) Liu, H.; Long, D.; Liu, X.; Qiao, W.; Zhan, L.; Ling, L. Facile Synthesis and Superior Anodic Performance of Ultrafine SnO2-Containing Nanocomposites. Electrochimica Acta 2009, 54 (24), 5782-5788. https://doi.org/10.1016/j.electacta.2009.05.030.

(13) Narsimulu, D.; Vadnala, S.; Srinadhu, E. S.; Satyanarayana, N. Electrospun Sn-SnO2/C Composite Nanofibers as an Anode Material for Lithium Battery Applications. J Mater Sci: Mater Electron 2018, 29 (13), 11117-11123. https://doi.org/10.1007/s10854-0189195-9.

(14) Hong, Y. J.; Son, M. Y.; Kang, Y. C. One-Pot Facile Synthesis of Double-Shelled SnO2 Yolk-Shell-Structured Powders by Continuous Process as Anode Materials for Li-Ion Batteries. Advanced Materials 2013, 25 (16), 2279-2283. https://doi.org/10.1002/adma.201204506. 
(15) Neimark, A. V.; Lin, Y.; Ravikovitch, P. I.; Thommes, M. Quenched Solid Density Functional Theory and Pore Size Analysis of Micro-Mesoporous Carbons. Carbon 2009, 47 (7), 1617-1628. https://doi.org/10.1016/j.carbon.2009.01.050.

(16) Brunauer, S.; Emmett, P. H.; Teller, E. Adsorption of Gases in Multimolecular Layers. J. Am. Chem. Soc. 1938, 60 (2), 309-319. https://doi.org/10.1021/ja01269a023.

(17) Thommes, M. Physical Adsorption Characterization of Nanoporous Materials. Chemie Ingenieur Technik 2010, 82 (7), 1059-1073. https://doi.org/10.1002/cite.201000064. 